\title{
A human multisubunit E3 ubiquitin ligase required for heterotrimeric G-protein $\beta$-subunit ubiquitination and downstream signaling
}

\author{
Brian D. Young ${ }^{1,2}$, Jihui Sha ${ }^{1}$, Ajay A. Vashisht ${ }^{1,3}$, and James A. Wohlschlegel ${ }^{1,2 *}$ \\ ${ }^{1}$ Department of Biological Chemistry and ${ }^{2}$ Molecular Biology Institute, David Geffen School of \\ Medicine, UCLA, Los Angeles, California 90095 \\ ${ }^{3}$ Genomics Institute of the Novartis Research Foundation, San Diego, California 92121 (current address) \\ *Corresponding author: James A. Wohlschlegel (jwohl@mednet.ucla.edu)
}




\section{SUPPORTING INFORMATION}

Figure S1. KCTD2 binds G $\beta$ in response to G-protein activation

Table S1. Spectral counting data for KCTD2/5/17 interactions with G-protein subunits

Table S2. Subset of interactors that differentially associate with GNB1-WT and GNB1-K15R/K23R

Table S3. List of cDNA plasmids

Table S4. List of PCR primers

Table S5. Peptide and protein identification tables and MSStats statistical outputs for MS analyses.

Supplemental PDF file containing uncropped images of Western blots 


\section{SUPPORTING INFORMATION}

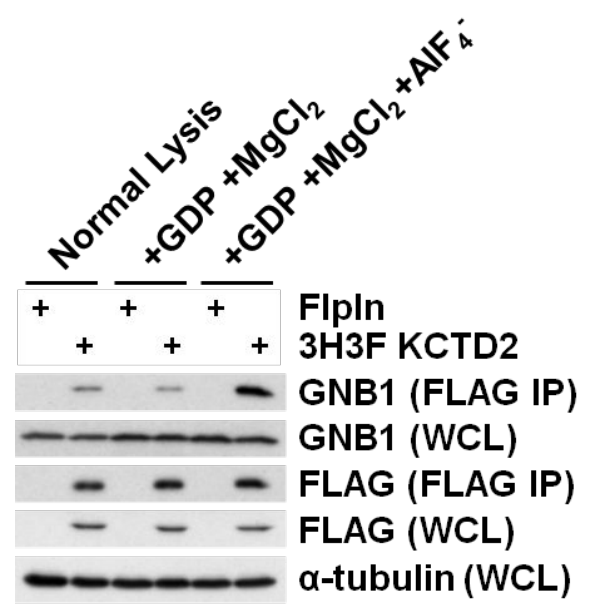

Figure S1: KCTD2 binds G $\beta$ in response to G-protein activation

HeLa control cells and cells stably expressing 3H3F-KCTD2 were lysed in the presence and absence of G-protein signaling activators $\left(\mathrm{AlF}_{4}^{-}, \mathrm{GDP}\right.$, and $\left.\mathrm{MgCl}_{2}\right)$. Immunoblots of whole-cell lysates (WCL) and anti-FLAG immunopurifications (FLAG IP) are shown. This is representative of two independent experiments. 
Table S1: Spectral counting data for the protein interactomes of the KCTD2/5/17 subfamily

\begin{tabular}{|c|c|c|c|c|}
\cline { 2 - 5 } \multicolumn{1}{c|}{} & \multicolumn{4}{c|}{ Bait } \\
\hline Prey & Control & KCTD2 & KCTD5 & KCTD17 \\
\hline KCTD2 & 0 & 335.75 & 21.75 & 44 \\
\hline KCTD5 & 0 & 27 & 181 & 86.5 \\
\hline KCTD17 & 0 & 49.75 & 62 & 526 \\
\hline CUL3 & 0 & 25.75 & 43.75 & 15.75 \\
\hline GNB1 & 0 & 153.75 & 42.5 & 4.25 \\
\hline GNB2 & 0 & 139 & 42.5 & 3.75 \\
\hline GNB4 & 0 & 83.5 & 28 & 2.5 \\
\hline GNG2 & 0 & 3.25 & 0 & 0 \\
\hline GNG4 & 0 & 2.75 & 0.25 & 0 \\
\hline GNG7 & 0 & 2.5 & 0.25 & 0 \\
\hline GNG12 & 0 & 16 & 5.5 & 0 \\
\hline
\end{tabular}

Anti-HA immunopurifications $(\mathrm{n}=2)$ from control HEK-293 cells and cells stably expressing 3H3Ftagged KCTD proteins were analyzed by mass spectrometry as described in Figure 2B. Columns and rows represent different bait and prey, respectively. Average spectral counts for select prey are shown. 
Table S2: Subset of Proteins Differentially Associated with GNB1 wildtype or GNB1-K15R/K23R

\begin{tabular}{l|l|c|c}
\hline \multicolumn{1}{c|}{ Protein } & \multicolumn{1}{|c|}{ Description } & iLog2FC (K15R/K23R : WT) & iPvalue \\
\hline GRK3 & Protein Kinase & -5.103 & 0.032 \\
PRKCI & Protein Kinase & -3.403 & 0.022 \\
YWHAH & Signaling Adapter & 4.162 & 0.014 \\
SLC39A11 & Zinc Transporter & -4.465 & 0.010 \\
SLC1A3 & Amino Acid Transporter & -2.522 & 0.012 \\
CLINT1 & Membrane Trafficking & 4.724 & 0.021 \\
VPS18 & Membrane Trafficking & -4.624 & 0.048 \\
\hline
\end{tabular}

GNB1 Immunoprecipitates ( $\mathrm{n}=2$ ) from control HEK-293 cells and cells stably expressing 3H3F-tagged GNB1 wildtype or GNB1-K15R/K23R were analyzed by mass spectrometry and quantified by MS1based label-free quantitation. $\log 2$ fold-changes and the p-values after imputation of missing values were calculated by MSStats and ArtMS. 
Table S3: List of cDNA Plasmids

\begin{tabular}{|c|c|c|c|}
\hline ORF & GenBank & Vendor & Catalog Number \\
\hline KCTD2 & BC160142.1 & GeneCopoeia & Y3428 \\
\hline KCTD5 & BC007314.2 & Dharmacon & MHS6278-202826872 \\
\hline KCTD17 & BC031038.1 & Dharmacon & MHS6278-202808680 \\
\hline GNAS & BC002722.2 & Dharmacon & MHS6278-202829474 \\
\hline GNB1 & BC005888.2 & Dharmacon & MHS6278-202829088 \\
\hline GNG12 & BC005940.1 & Dharmacon & MHS6278-202839798 \\
\hline CUL3 & BC092409.1 & Dharmacon & MHS6278-202759865 \\
\hline
\end{tabular}


Table S4-List of PCR Primers

\begin{tabular}{|c|c|}
\hline Primer & Sequence \\
\hline $\begin{array}{l}\text { KCTD5 } \\
\text { Forward }\end{array}$ & $\begin{array}{l}\text { 5'-GGG GAC AAG TTT GTA CAA AAA AGC AGG CTC CGC GGA GAA TCA } \\
\text { CTG CGA G-3' }\end{array}$ \\
\hline $\begin{array}{l}\text { KCTD5 } \\
\text { Reverse }\end{array}$ & $\begin{array}{l}\text { 5'-GGG GAC CAC TTT GTA CAA GAA AGC} \text { TGG GTC TTA TCA CAT CCT TGA } \\
\text { GCC TCG TTC-3' }\end{array}$ \\
\hline $\begin{array}{l}\text { KCTD17 } \\
\text { Forward }\end{array}$ & $\begin{array}{l}\text { 5'-GGG GAC AAG TTT GTA CAA AAA AGC AGG CTC CAG GAT GGA GGC } \\
\text { CGG GGA G-3' }\end{array}$ \\
\hline $\begin{array}{l}\text { KCTD17 } \\
\text { Reverse }\end{array}$ & $\begin{array}{l}\text { 5'-GGG GAC CAC TTT GTA CAA GAA AGC TGG GTC TTA TCA GAT GGG AAC } \\
\text { CCC AAG TCC-3' }\end{array}$ \\
\hline $\begin{array}{c}\text { GNAS } \\
\text { Forward }\end{array}$ & $\begin{array}{l}\text { 5'-GGG GAC AAG TTT GTA CAA AAA AGC AGG CTC CGG CTG CCT CGG } \\
\text { GAA CAG T-3' }\end{array}$ \\
\hline $\begin{array}{l}\text { GNAS } \\
\text { Reverse }\end{array}$ & $\begin{array}{l}\text { 5'-GGG GAC CAC TTT GTA CAA GAA AGC TGG GTC TTA TTA GAG CAG CTC } \\
\text { GTA CTG ACG-3' }\end{array}$ \\
\hline $\begin{array}{c}\text { GNB1 } \\
\text { Forward }\end{array}$ & $\begin{array}{l}\text { 5'-GGG GAC AAG TTT GTA CAA AAA AGC AGG CTC CAG TGA GCT TGA } \\
\text { CCA GTT ACG G-3' }\end{array}$ \\
\hline $\begin{array}{l}\text { GNB1 } \\
\text { Reverse }\end{array}$ & $\begin{array}{l}\text { 5'-GGG GAC CAC TTT GTA CAA GAA AGC TGG GTC TTA TTA GTT CCA GAT } \\
\text { CTT GAG GAA GCT-3' }\end{array}$ \\
\hline $\begin{array}{l}\text { GNG12 } \\
\text { Forward }\end{array}$ & $\begin{array}{l}\text { 5'-GGG GAC AAG TTT GTA CAA AAA AGC AGG CTC CTC CAG CAA AAC } \\
\text { AGC AAG CAC C-3' }\end{array}$ \\
\hline $\begin{array}{l}\text { GNG12 } \\
\text { Reverse }\end{array}$ & $\begin{array}{l}\text { 5'-GGG GAC CAC TTT GTA CAA GAA AGC TGG GTC TTA} \text { CTA TAA GAT GAT } \\
\text { GCA AGT TTT TTT ATC CTT-3' }\end{array}$ \\
\hline $\begin{array}{l}\text { CUL3 } \\
\text { Forward }\end{array}$ & $\begin{array}{l}\text { 5'-GGG GAC AAG TTT GTA CAA AAA AGC AGG CTC CTC GAA TCT GAG } \\
\text { CAA AGG CAC G-3' }\end{array}$ \\
\hline $\begin{array}{l}\text { CUL3 } \\
\text { Reverse }\end{array}$ & 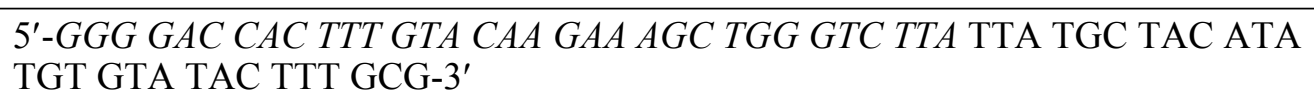 \\
\hline
\end{tabular}

Underlined and italicized sequences mark the attB1 and attB2 sequences, respectively. 